J. Lake Sci. (湖泊科学), $2006, \mathbf{1 8}(3): 193-198$

http:// www. jlakes. org. E-mail: jlakes@ niglas. ac.cn

(c) 2006 by Journal of Lake Sciences

\title{
太湖流域水污染控制与生态修复的研究与战略思考"
}

\author{
中国科学院南京地理与湖泊研究所
}

\begin{abstract}
摘 要: 在分析了太湖及其流域所面临的水环境质量问题及其原因基础上, 回顾总结了 “十五”太湖水环境治理经验, 认 为源头控制需要长期不解的努力,太湖流域的湖泊治理要针对太湖平原河网与湖荡水系特色,要重视太湖东部草型湖区 生态环境恶化的严重性,必须加强生态修复单项技术间的效应优化和有效集成. 根据太湖流域的社会经济发展规划, 提 出了太湖流域水污染控制技术与水体生态修复工程示范的总体思路是: 从污染源头到湖泊出口, 依次通过污染源控制、河 道截污、湖荡调节、河口净化、湖泊生态修复、出湖疏导等多道防线,有效促使太湖水环境向良性方向转化. 在此基础上提 出了具体实施建议: 全流域污染源削减和太湖水源地典型水域生态修复技术集成与工程示范,同时进行全流域水环境治 理强化管理政策与决策支持技术的研究与示范.
\end{abstract}

关键词:太湖流域;水污染控制;生态修复;战略思考

\section{Research and strategic thinking for water pollution control and ecological restoration in Taihu Basin}

\author{
Nanjing Institute of Geography and Limnology, Chinese Academy of Sciences, P. R. China
}

\begin{abstract}
The situation of water environmental quality and its causation in Taihu Basin was analyzed. The experience of water environmental management in the $10^{\text {th }}$ five-year project was summarized. It is proposed that pollutant source control be implemented for a long time. Management in Taihu Basin must consider the characteristics of its plains and network of waterway. The ponderance of typical macrophytic lake ecological deterioration should be recognized. We need to optimize each technique used in lake ecological restoration and emphasize on their combination. Based on social-economic development program in Taihu Basin, we put forward our strategic thinking for the control of pollution and water remediation in the future, which was implemented successively by pollutant source control, watercourse pollutant collection, small lake and marshes regulation, estuary intensity purification, lake ecological restoration, outflowing leading, et al. All these steps could accelerate the improvement of water quality in Taihu Basin. We proposed technique combination and project demonstration of whole basin pollutant reduction and ecological restoration of representative district of drinking water sources, and also suggested the development and demonstration of water environmental management policy and supported techniques.
\end{abstract}

Keywords: Taihu Basin; water pollution control; ecological restoration; strategic thinking

太湖是我国第三大淡水湖,太湖流域是我国举足轻重的经济核心区和城市密集区. 土地面积和人口不 足全国的 $0.4 \%$ 和 $3 \%$ 的太湖流域,创造了 $13 \%$ 左右的国内生产总值和 $20 \%$ 左右的财政收人. 到 2010 年, 太湖流域预计 GDP 将从 2000 年的 9717 亿增加到 20380 亿, 人口则由 4264 万增加到 4710 万. 因此随着经 济快速发展和人口迅猛增加, 如果不加大治理力度, 采取有效措施, 水环境污染问题将会更加突出. 如何在 未来的 “十一五” 期间,全面加强太湖及其流域水环境综合整治与水质改善,解决社会经济发展与水资源利 用、水环境保护的矛盾已成为政府与公众日益关注的焦点. 国家中长期科学和技术发展规划纲要 (资源环 境领域)和国务院《关于落实科学发展观加强环境保护的决定》对 “十一五”期间水体污染的控制与治理， 
确保供水安全和人体健康提出了具体要求. 本文在剖析太湖及其流域水环境质量现状与趋势, 总结 “十五” 水环境治理经验的基础上, 根据社会经济发展规划, 提出太湖流域水污染控制技术与水体生态修复工程示 范的总体思路与建议.

\section{1 太湖及其流域所面临的主要水环境问题与原因分析}

\section{1 太湖流域所面临的主要水环境污染问题}

1.1.1 太湖富营养化程度依然十分严重 自 1990 年代出现大规模藻类水华并诱发严重的环境问题以来， 太湖富营养化引起了各级政府与科学界的高度重视. 先后开展了“零点行动”、含磷洗涤剂禁用、“引江济 太” 等水环境改善措施, 对遏制水环境恶化起到了积极的作用. 但目前流域内河湖水质仍然未得到根本改 善 ${ }^{[1]}$. 目前太湖流域河流水质全年综合评价超标河长为 $84 \%$, 大部分为 $\mathrm{V}$ 类和劣 $\mathrm{V}$ 类,特别是总磷 $(\mathrm{TP})$, 污染十分严重. $2001-2005$ 年监测结果证实, 主要人湖河流与湖荡出现进一步恶化的趋势, 如太滆运河 (黄 埝桥) TP 由 $0.091 \mathrm{mg} / \mathrm{L}$ 上升到 $0.252 \mathrm{mg} / \mathrm{L}$; 武进港(姚巷桥) TP 由 $0.073 \mathrm{mg} / \mathrm{L}$ 上升到 $0.171 \mathrm{mg} / \mathrm{L}$, 氨氮浓 度达 $1.86 \mathrm{mg} / \mathrm{L}$ ，也处于超标状态. 地处上游的湖荡如滆湖总氮 $(\mathrm{TN})$ 由 $1.940 \mathrm{mg} / \mathrm{L}$ 上升到 $3.927 \mathrm{mg} / \mathrm{L}, \mathrm{TP}$ 由 $0.081 \mathrm{mg} / \mathrm{L}$ 上升到 $0.150 \mathrm{mg} / \mathrm{L}$; 长荡湖近 3 年来 $\mathrm{TN}$ 由 $1.23 \mathrm{mg} / \mathrm{L}$ 上升到 $1.82 \mathrm{mg} / \mathrm{L}, \mathrm{TP}$ 由 $0.136 \mathrm{mg} / \mathrm{L}$ 上 升到 $0.194 \mathrm{mg} / \mathrm{L}$. 上游人湖河流和湖荡地区水质持续恶化直接导致太湖入湖污染物总量不断增加. 据统 计,1987 年, 人湖 $\mathrm{TP}$ 仅为 $1326.69 \mathrm{t}$, TN 为 $26020 \mathrm{t}^{[2]}$; 而到 2002 年, 分别达 $1890 \mathrm{t}$ 和 $44600 \mathrm{t}^{[3]}$. 受人湖污染物 增加的影响,太湖水体中的 TP、TN 含量在 2001-2002 年曾一度有所下降后,继续呈上升趋势 (图 1). 尤其 是大浦口水域近四年 TP、TN 浓度上升速度较快. 此外, 太湖湖心藻类叶绿素 a 含量呈逐年上升趋势, 2004 年均值超过或接近 $20 \mu \mathrm{g} / \mathrm{L}$, 可见藻类水华已经由梅梁湾向湖心、东太湖扩展, 因此, 太湖水污染和富营养化 状况依然十分严重.
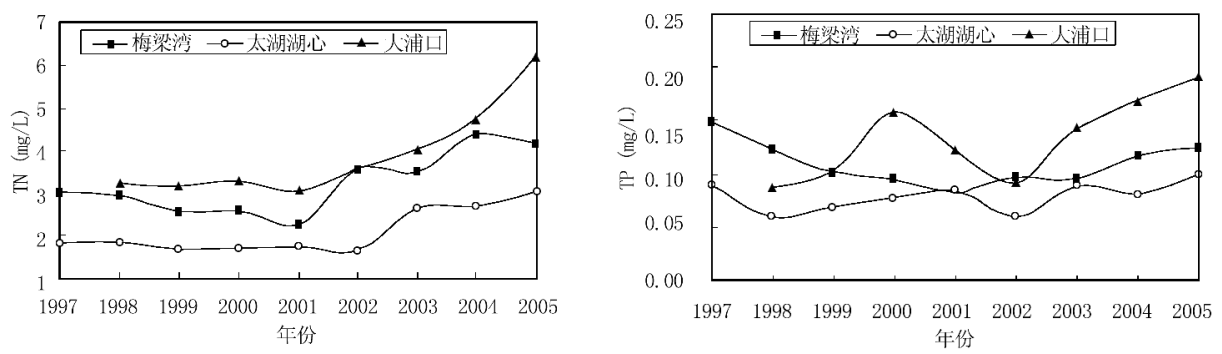

图 $11997-2005$ 年梅梁湖湾心、太湖湖心及大浦口水域 TN、TP 年均值变化

Fig. 1 Variation of TP, TN in center of Meiliang Bay, center of Lake Taihu and the estuary of Dapu River from 1997 to 2005

1.1 .2 复合污染威胁着湖泊水源地和水产品的安全 早期的工业污染和目前仍然存在的农药、集约化畜禽 养殖中激素、抗生素的使用, 导致了新的湖泊复合污染问题 ${ }^{[4,5]}$. 虽然这些污染物的浓度处于微量或痕量水 平, 但由于生物积累与放大过程和多种污染物的联合效应, 给饮用水安全、水产品品质以及人体健康带来严 重威胁. 有关检测表明, 目前太湖表层沉积物中检出优先控制污染物 21 种, 表层水检测到 37 种持久性有 机污染物,生态毒理学检测表明其具有较强的毒性. 太湖鲤鱼肌肉中曾检测到二恶英毒性当量达 $3 \mathrm{pg} / \mathrm{g}$ $(\mathrm{ww})$ (欧盟制订的食品标准中规定为 $4 \mathrm{pg} / \mathrm{g}(\mathrm{ww})$ ). 五里湖疏浚底泥堆场中, 在堆泥前植物体内不存在的 多环芳烃 $(\mathrm{PAHs})$, 如苯并 $[\mathrm{a}]$ 葸和屈等,在堆放底泥后被检出, 说明这些物质来自于疏竣底泥的污染. 堆场 使用 8 个月后,生长其间的植物体内 PAHs 含量增加 6 倍, 显示了强烈的累积作用. 因此在湖泊治理过程 中, 在控制营养盐的同时还应关注微量有毒有害物质的生态风险评价与去除 (1).

\section{2 水环境污染加重的原因分析}

1.2.1 工业化、城市化高速发展, 污染物绝对排放量增加 近十多年来,太湖流域的工业产值特别是太湖沿 
岸的乡镇工业产值翻了 2-3 番, 因此, 尽管实施了达标排放, 但排放总量却不断在增加. 如常州市 2004 年 全市工业 COD 排放量达到 43000t, 整个区域每年有近 $10 \times 10^{8} \mathrm{t}$ 的工业污水未经妥善处理排人河道和湖泊. 太湖流域的城市化过程导致人口急剧增加,2005 年流域城镇化水平已经达到 $66.5 \%$, 人口密度达 1000 人 $\mathrm{km}^{2}$, 再加上数百万流动人口, 城镇面源污染 TN、TP 增加量最高达 $20 \%$. 全流域城镇生活污水排放量达到 $2.2 \times 10^{8} \mathrm{t}$, 成为流域内污染物的主要来源之一 ${ }^{[6]}$.

1.2 .2 农村面源污染未能得到有效遏制 农村过量使用的化肥、农药随径流进人沟渠和河流, 最后进人太 湖. 据测算, 2004 年仅常州市氮肥流失量就达到 9233t, 磷肥流失量为 1103t. 同时, 由于农村生活方式的城 镇化, 而废弃物的收集和处置以及污水管网水平却严重滞后 ${ }^{[7,8]}$, 随着雨水冲刷进人河流. 更值得关注的是 环太湖流域有大约 2000 多家集约化畜禽养殖场, $85 \%$ 的养殖场畜禽粪便直接排人太湖和附近河道, 在 20 世纪 90 年代太湖流域人湖的畜禽粪便就高达 $200 \times 10^{4} \mathrm{t} / \mathrm{a}$, 约为工业固体废弃物的 3 倍. 例如, 2004 年常州 市畜禽养殖 COD 排放量达到 6700t, TN 排放量达到 1300t, TP 排放量近 600t.

1.2 .3 渔业养殖规模与强度过大, 对水土环境影响明显 据 2002 年卫星遥感影像估算, 东太湖养殖面积已 达约 $11000 \mathrm{hm}^{2}$. 对养殖区底泥逐年调查分析表明, 养殖 4 年后, 底泥中有机质、TN 和 TP 含量分别增加了 $116.9 \% 、 90.5 \%$ 和 $55.6 \%$, 水体中营养物含量随养殖规模和放养密度的增加而呈升高趋势, 水质明显恶化. 据估算, 东太湖底泥每年氮磷释放总量已成为全太湖的主要内源污染贡献者之一 ${ }^{[9]}$.

1.2 .4 流域河网湖荡生态系统功能退化, 对污染物净化和拦截能力下降 太湖上游地区水网发达, 天然湖 荡密布, 对流域污染物拦截和水质净化具有重要作用 ${ }^{[10]}$. 但是近年来受城市化、水体高密度养殖 ${ }^{[11]}$ 、污染 排放增加等影响, 河网湖荡水体生态退化严重, 严重削弱和降低其对污染物转化和拦截功能. 以滆湖为例, 1998 年以前水草资源十分丰富, 水草覆盖率保持在 $80 \%$ 以上, 水体透明度高。到 2004 年水草覆盖已不足 $10 \%$. 由于以水草大量消失为表征的水体生态系统退化, 使滆湖丧失了过滤与蓄积水体 TN、TP 的能力, 太 湖失去了拦截营养盐的第一道天然屏障, 导致太滆运河段入湖水体 TP 含量年均值高达 $0.252 \mathrm{mg} / \mathrm{L}$, 对太 湖水质保护极为不利. 太湖流域水体水质分布总体特征是湖泊好于河道, 山区水体好于平原河网 ${ }^{[12]}$.

1.2.5 河湖底泥中污染物累积加重, 内源负荷增加 城市和农村排人河湖的污染物长年积累在河道、湖泊 底泥中 ${ }^{[13-15]}$, 频繁的风浪作用以及大量运输船舶摚动所产生的底泥污染物释放现象极为普遍, 成为继农村 面源、城市污水之后又一重要的二次污染源 ${ }^{[16-18]}$. 在太湖上游的常州市, 近年来河道的清淤量仅为其淤积 量的 60\%-70\%. 武进港、大通河、北塘河等河流受到底泥污染物二次污染尤其明显, 因此环太湖人湖河道 污染负荷的增加是太湖水环境恶化的根本原因 ${ }^{[19,20]}$.

1.2 .6 污染治理的投入强度相对不足, 治理的重点不突出 近年来, 太湖流域国民生产总值的快速增长和 城镇人口的急剧增加导致了污染排放量大幅度增加, 但水污染的治理力度却无法与其相适应. 例如太湖上 游及沿湖地区城市污水处理大多仍为 $1-2$ 级处理, 技术上难以满足脱氮除磷的要求 ${ }^{[21]}$.

\section{2 “十五”太湖水环境治理进展与剖析}

为体现从点源控制向点源与面源控制相结合、从城市污染控制为主向城市与农村污染控制相结合、从 陆上污染控制为主向陆上与水体污染控制相结合的转变, 2001 年国务院批复实施了《太湖水污染防治“十 五”计划》, 提出了“十五” 的治污工程、生态恢复工程和强化管理三大工程. 在湖泊富营养化的基础研究方 面, 主要有国家重点基础研究发展计划(973) “湖泊富营养化过程与蓝藻水华暴发的机理研究” 和“土壤质 量演变规律与持续利用” 以及中国科学院重大方向性项目 “长江中下游湖泊富营养化过程机理与对策研 究” 等一系列基础研究. 在太湖流域针对农村面源、湖泊水源地的水质改善和重污染湖区的底泥疏浚与生 态重建等方面开展了湖泊治理的技术集成与工程示范. 开发了农村面源污染削减的成套技术; 集成和创建 了在恶劣条件下保护和改善湖泊水源地水质的综合治理技术; 并建立了环保疏浚和生态重建的技术和示范 工程 ${ }^{1}$. 同时针对苏州市河道污染和镇江城市水环境污染, 研究和开发了城市河网水动力分级循环及水量 自动控制技术、局部重污染河道水质改善的生物 - 生态协同调控技术和综合运用水利、环境、生态手段, 进 
行水环境质量改善和生态修复.

布庸置疑, 通过以上卓有成效的大范围、大规模的工程示范, 提升了科学治理太湖流域水环境的理念, 为进一步的生态修复奠定了较好的基础. 但是由于示范工程运行时间比较短,且所进行的各个示范工程是 在不同地区展开,比较分散,未能形成一个较为完整的系统,规模相对较小的局部生态修复示范工程区处在 污染严重,外源和内源污染还无法完全控制的这样一个完全开放的背景下,很难评价这些工程在改善太湖 水质、控制流域污染方面的贡献. 因此, 未来的太湖流域的水环境治理还有待在以下方面有所加强:

\section{1 源头控制需要长期不解的努力}

农业源头营养盐和有机有毒污染物的控制需要更多的技术支撑以及新的管理理念. 尤其需要结合建 设社会主义新农村,推进生态村镇、生态农业、有机农业示范区的建设. 从“十五”太湖面源控制的研究成果 看, 城镇化的农村污染物控制需要长效管理和技术集成,特别是要加强面源污染与水网之间的联系的研究, 评价面源控制成效,并根据农村面广量大的实际情况进行长期不解的努力.

\section{2 湖泊治理要重视太湖上游河网湖荡生态与环境的修复}

太湖流域河网密布, 大小河流 100 多条, 湖荡水塘近 200 多个,彼此综横交错, 水动力条件复杂,一旦受 到污染, 会沿河网到处扩散,治理难度较大. 监测结果表明, 目前进行的陆上的单个控制和截留技术的效 果, 很难从河道控制断面的数据上得到反映,其主要原因可能是尚未抓住太湖流域河网交错与湖荡密布的 水文地貌特点. 一旦污染物进人河网后, 其污水团的输移规律与一般河流有着很大区别. 而湖荡作为河网 的结点, 不仅有容纳污染物的功能, 还可能起着调节污染物在与之相连河道中分配的作用, 同时, 湖荡可以 利用自身对污染物的净化和生态吸收的功能, 使污染物在人太湖前就得到较大程度的削减.

\section{3 要认识太湖草型湖区生态与环境恶化的严重性}

太湖东部草型湖区是上海 (东太湖)、苏州 (胥湖) 和无锡市 (贡湖) 的重要水源地而倍受人们关注. 但 是由于对水质表观数据认识的限制, 其近十年来逐渐出现水体环境恶化和资源退化问题, 并未受到人们的 实质性重视. 如水草覆盖度最大可达 $95 \%$ 以上的东太湖湖区, 近年来由于网围养殖的过度和无序发展, 阻 碍了对东太湖水生植被的利用. 同时养殖品种的单一化, 使得东太湖优质水生植被资源量下降, 有机质的 过量积累以及水草死亡残体分解, 导致内源污染严重、河道淤积、水草退化、沼泽化并影响下游泄洪等 ${ }^{[19]}$.

\section{4 加强生态修复单项技术间的效应优化和有效集成}

“十五” 期间用于示范工程的各单项技术效果十分明显,但是其集成的总体效果由于工程实施时间短, 有待生态系统的恢复和稳定才能体现, 因此技术应用的成效还未能充分显示; 同时,在不同技术的效应方面 还需要系统的比较、笁选和优化组合, 明确各单项技术对污染物去除的实际贡献率和适用条件. 另外, 目前 的技术集成更多的是一种空间上的组合,各单项技术的内在有机衔接还不够,例如对水体氨氮的有效去除 还需要发展适合大水面示范工程的技术及其集成 (1.

\section{3 太湖及其流域水环境治理的对策}

\section{1 太湖及其流域水环境治理的总体思路}

太湖及其流域社会经济快速发展和生态与环境保护出现的矛盾凸现出太湖水环境治理的紧迫性和艰 巨性. 只有从污染源头到湖泊出口, 依次通过污染源控制、河道截污、湖荡调节、河口净化、湖泊生态修复、 出湖疏导等多道防线,有效促使太湖水环境向良性方向转化.

（1）源头控制: 即通过土地利用类型与农业种植结构的调整, 控制化肥农药施用和农村畜禽养殖, 推 广生活节水措施,减少生活污水产出量, 加大污水处理力度,减少面源污染; 这是实现太湖流域水环境治理 目标的最重要前提.

（2）河道截污: 利用已有的水利工程设施,调整流域河网水系功能结构和水力过程,保育植被,恢复景 观生态, 有效发挥灌木和水生植物的水质净化功能, 充分利用河网水系对流稀释、动力复氧、沉降吸附能力, 建立生态干流与河渠,削除进入流域湖荡的污染物. 
（3）湖荡调节: 利用太湖上游大大小小湖荡, 调控湖荡水力结构及生态系统结构, 发挥湿地生态功能, 拦截污染物, 改善湖荡出流水质,减少人太湖污染物总量.

(4) 河口净化: 充分发挥人湖河口的河 - 湖生态系统交界处生态系统高度活跃的特点, 通过建设河口 湿地生态屏障,阻滞、过滤污染物质进入湖泊. 改善河口区的水力条件,强化水体自净能力.

(5) 湖泊生态修复: 根据太湖水力特点, 对入湖污染物采取工程措施, 阻挡污染物向重点饮用水源区 输移,重点保证水源地的水质改善和饮用水安全, 同时恢复或者重建生态系统,达到全面、长效改善太湖流 域水质的目的.

(6) 出湖疏导: 通过对出湖水量的生态调控,严格控制养殖规模, 充分利用太湖进出水量大,水利工程 设施引排能力强的特点, 合理进行疏导, 优化调控方案, 改善出湖区水环境, 保证出水水质水量.

\section{2 太湖水污染控制与生态修复工程示范实施建议}

根据太湖周边地区的社会经济发展对水环境的要求,在近期太湖水环境治理中,应继续完成“十五”期 间所提出的目标,贯彻“未端治理、源头控制” 的原则,根据新的技术思路,太湖的水质改善不能仅仅局限于 太湖水体,而应该加强削减流域污染,充分发挥太湖流域的湖荡与河网的净化作用,修复与保护流域的生态 结构与功能, 提高其自净能力, 削减人湖污染负荷. 在此基础上, 在湖泊内重点水源地开展有效的生态修复 与重建工程.

3.2 .1 全流域污染源削减技术集成与工程示范 太湖流域最大的特点就是河网交错, 河网面积要比太湖水 面大,河网区也是人口密集和污染产生的主要区域,而且河网中有很多盲河和断头浜的湖荡,多年来面源污 染随径流进人这些河网, 沉积在河道和湖荡中, 多年未清淤, 内源污染十分严重.

可见,对于太湖来说,上游的河流与湖荡一方面起到 “大型”前置库的作用,拦截了大量的污染物,减少 了人湖污染的总量; 但是另一方面, 其储存的污染物又会因为洪水发生而进人太湖,在充分发挥河道与湖荡 生态拦截功能作用的同时, 还必须考虑如何及时对河道和湖荡进行生态修复, 去除长期储存的大量污染物, 以保证其生态拦截作用得已持续, 降低其向大太湖输移污染物的风险, 这对保证太湖水源地的供水安全是 十分重要的前提. 而面源污染物经由河流与湖荡进人是太湖流域的基本的格局. 进人太湖水体的 60 余条 人湖河流,其中 13 条人湖河流污染负荷 $\left(\mathrm{TP} 、 \mathrm{NH}_{3}-\mathrm{N}\right)$ 占全部河流人湖总量的 $70 \%$ 以上. 因此选择其河网系 统进行生态修复和环境治理将有希望解决目前局部治理对整个太湖水环境质量改善说不清楚的尴尬. 同 时在所选择的河网区所进行的示范工程可以系统地开发河网区污染削减技术, 成熟以后在太湖流域的其他 几个主要人湖河网区逐步推广, 经过多年乃至几个五年计划的的努力, 应该可以大量削减并有效控制从这 些主要人湖河网区进人太湖的污染物总量,达到“太湖水变清”的最终目标.

针对太湖流域的河网特色以及面源污染还暂时无法完全控制的情况,建议选择不同类型的、人湖污染 负荷适当的典型河网区,首先在该河道的源头进行污水处理厂尾水脱氮除磷的工艺技术集成与工程示范， 结合生态示范村 (镇) 和有机农业示范区的建设,开展削减污染面源的技术集成和强化管理示范; 充分发挥 太湖流域的湖荡与河网的净化作用, 在河道和湖荡进行生态修复技术集成与示范工程, 辅以水力调节和生 态清淤, 提高其自净能力, 削减人湖污染负荷; 一直到该河道的人湖河口进行人工湿地的景观建设和污染物 强化净化; 并在湖滨带进行景观岸带水生植被修复技术集成与示范工程,这样形成该河网区削减流域污染 物的系统工程. 因为以上不同环节涉及到不同类型的水生生态系统,既有农村, 又有河道与河网, 同时还有 湖荡和湖滨带, 而从该河网区域来看, 又是处于同一个大系统中, 各个子系统彼此紧密关联. 在实施过程 中, 既可以获得不同类型生态系统恢复与重建的技术集成和示范工程的成效, 依据效果, 不断调整, 逐步完 善. 同时也为其他河网区进行水环境治理提供示范, 既有长期规划, 又具有一定的可操作性,逐步达到全流 域的水污染控制目标.

3.2 .2 太湖水源地典型水域生态修复技术集成与工程示范 太湖作为无锡、常州、上海和浙江十多个大、中 城市的水源地, 取水口多达 40 多个,惠及人口上千万人,因此在努力削减人湖污染物的同时, 大太湖当今最 重要的治理任务仍然是水源地的保护和局部水体的污染控制. 目前太湖的水源地有梅梁湾, 为藻型湖泊, 而草型湖泊的东太湖作为重要的战略水源地,同样也面临着富营养化和沼泽化的难题. 这两种不同类型的 湖泊, 都属于生态系统的结构与功能发生了退化, 只是向不同的方向发展. 因此通过对不同类型的湖泊水 
源地进行生态修复,可以继续巩固 “十五” 期间对水源地进行水质改善的生态修复技术集成与工程示范的 成效,同时确定不同类型富营养化湖区的水源地水质改善所需要的不同生态修复技术类型;而且两种类型 的富营养化湖泊在太湖及全国均具有代表性, 有很好的示范作用. 因此建议在太湖选择梅梁湾和东太湖两 个不同类型的湖区的水源地,进行水质改善的生态修复的技术集成与工程示范.

在梅梁湾继续进行饮用水源地基础生境构建、饮用水源地的藻类控制技术与优化、饮用水源地的有毒 有机污染物控制、饮用水源地的安全预警系统与突发污染事件应急方案、不同生境条件下的饮用水源地安 全供水保障技术及其长效运行与管理模式等技术集成与示范工程; 根据东太湖水源地的生态系统特征, 进 行出流湖区生态退化调控与综合治理的技术集成与示范工程.

3.2 .3 全流域水环境治理强化管理政策与决策支持技术 “十五”的经验表明,流域的水环境治理不仅仅 需要技术支撑, 同时还迫切需要根据太湖流域污染控制与水环境管理的实际情况, 贯彻整体布局、综合协 调、人水和谐的原则,综合应用行政、市场、规划、法律等手段,建立流域水环境污染综合治理与管理的政策 体系和科学决策模式,为污染控制技术综合应用分析,治污工程效益评价、环境政策影响预测等环境管理提 供科学决策工具. 因此建议研究制订河湖体系功能综合优化模式与流域开发空间管理政策、流域环境容量 优化配置市场调节机制与总量控制政策、污染综合控制的生态经济政策与经济补偿措施、资源性湖泊行业 责权利分担体制和可操作监控管理体系、流域信息整合与模型交叉集成决策支持技术、重大科研课题形成 的示范工程长效管理与运行模式等.

致谢: 常州市环境监测站提供了大量数据; 图 1 数据以及叶绿素数据由中国科学院太湖湖泊生态系统研究 站监测、提供; 本文撰写过程中, 屠清瑛、秦伯强、李文朝和杨桂山等提出修改意见,一并表示感谢.

\section{4 参考文献}

[1] 黄文钰,杨桂山, 许朋柱. 太湖流域 “零点” 行动的环境效果分析. 湖泊科学, 2002, 14(1):67 -71.

[2] 黄渏平等. 太湖水污染及其污染控制. 北京:科学出版社,2001.

[3] 翟淑华,张红举. 环太湖河流进出湖水量及污染负荷 $(2000-2002$ 年). 湖泊科学, 2006,18(3):225-230.

[4] 张 路, 范成新, 秦伯强等. 太湖宜溧河水系沉积物中多环芳烃来源解析. 地球化学, 2003, 32(2): 124 - 130.

[5] 董克虞. 畜禽粪便对环境的污染及资源化途径. 农业环境保护, 1998,17(6): 12 - 17 .

[6] 李兆富,杨桂山. 太湖流域非点源污染特征与控制. 湖泊科学,2004,16(增刊) :83-87.

[7] 刘永德, 何品晶,邵立明等. 太湖流域农村生活垃圾产生特征及其影响因素. 农业环境科学学报, 2005,24 (3) :533 - 537.

[8] 刘润堂,许建中. 农业面源污染对湖泊水质影响的初步分析. 中国水利,2002, 6:54-56.

[9] 范成新, 张 路, 秦伯强等. 太湖沉积物 - 水界面生源要素迁移机制及定量化- - I. 铵态氮释放速率 的空间差异及源汇通量. 湖泊科学,2004,16(1) :10-20.

[10] 薛朝霞, 汪 羽, 阮晓红等. 引水冲污治理苏州的水环境. 中国给水排水,2002,18(10): $33-35$.

[11] 黄文钰, 许朋柱, 范成新. 网围养殖对骆马湖水体富营养化的影响. 农村生态环境, 2002, 18(1): $22-25$.

[12] 许朋柱, 秦伯强. $2001-2002$ 水文年环太湖河道的水量及污染物通量. 湖泊科学, 2005,17(3)213-218.

[13] 张 路, 范成新, 池俏俏等. 太湖及其主要入湖河流沉积磷形态分布研究. 地球化学, 2004, 33(4) : 423-431.

[14] 朱广伟, 陈英旭, 周根娣等. 运河 (杭州段)沉积物耗氧物质释放的模拟实验研究. 环境污染与防治, $2002,24(4)$ : $232-235$.

[15] 范成新, 张路, 池俏俏等. 太湖宜溧河和西苕溪干流沉积物中磷形态分布特征. 河海大学学报 ( 自然 科学版), 2002, 30(增刊) : $23-27$.

[16] 朱广伟,秦伯强, 高光. 风浪扰动引起大型浅水湖泊内源磷爆发性释放的直接证据. 科学通报,2005, 50(1) : $66-71$.

[17] 朱广伟, 秦伯强, 高 光. 强弱风浪扰动下太湖的营养盐垂向分布特征. 水科学进展, 2004, 15(6): $775-780$.

[18] 范成新, 张 路, 秦伯强等. 风浪作用下太湖悬浮态颗粒物中磷的动态释放估算. 中国科学 ( D 辑), $2003,33(8): 760-768$.

[19] 白秀玲,谷孝鸿,杨龙元. 东太湖水环境现状保护对策. 湖泊科学, 2006, 18(1):91-96.

[20] 谷孝鸿,张圣照, 白秀玲等. 东太湖水生植被群落结构的演变及其沼泽化研究. 生态学报, 2005,25 ( 7 ) : $1541-1548$.

[21] 沈光范. 关于城市污水处理厂设计的若干问题. 中国给水排水,2000,16(3):20-23. 